\title{
Detection of Toxocara cati Larvae from Ostrich and Wild Boar Meat Intended for Human Consumption
}

\author{
Alice Michelutti *, Sofia Sgubin, Christian Falcaro (D), Valentina Cagnin, Alessia Zoroaster and Patrizia Danesi \\ Parasitology, Mycology and Medical Enthomology Laboratory, Istituto Zooprofilattico Sperimentale delle \\ Venezie, Legnaro, 35020 Padova, Italy; ssgubin@izsvenezie.it (S.S.); cfalcaro@izsvenezie.it (C.F.); \\ vcagnin@izsvenezie.it (V.C.); azoroaster@izsvenezie.it (A.Z.); pdanesi@izsvenezie.it (P.D.) \\ * Correspondence: amichelutti@izsvenezie.it
}

Citation: Michelutti, A.; Sgubin, S.; Falcaro, C.; Cagnin, V.; Zoroaster, A.; Danesi, P. Detection of Toxocara cati Larvae from Ostrich and Wild Boar Meat Intended for Human Consumption. Pathogens 2021, 10, 1290. https://doi.org/10.3390/ pathogens 10101290

Academic Editors: Donato Traversa, Angela Di Cesare and Simone Morelli

Received: 6 August 2021

Accepted: 6 October 2021

Published: 7 October 2021

Publisher's Note: MDPI stays neutral with regard to jurisdictional claims in published maps and institutional affiliations.

Copyright: (c) 2021 by the authors. Licensee MDPI, Basel, Switzerland. This article is an open access article distributed under the terms and conditions of the Creative Commons Attribution (CC BY) license (https:/ / creativecommons.org/licenses/by/ $4.0 /)$.
Abstract: Toxocara cati is a common roundworm of cats and wild felids and, together with T. canis, it is the main causative agent of human toxocariasis. Humans may become infected by ingestion of embryonated eggs via contaminated soil, food, or water, or by ingestion of raw or undercooked meat of paratenic hosts that are infected by Toxocara larvae. In this study, we report the detection of T. cati larvae from meat samples of ostriches and wild boars. These samples were inspected by enzymatic digestion, as part of the trichinellosis surveillance. As ostrich meat is intended for "carpaccio" preparation, a traditional Italian raw meat preparation, there is the need to make the consumption of this meat safe. For this purpose, it is recommended to freeze the meat before preparation. Our findings confirmed that $T$. cati larvae can contaminate muscle tissues of paratenic hosts, increasing the risk of infection due to the consumption of raw or undercooked meat.

Keywords: Toxocariasis; Toxocara cati; meat; ostrich; wild boar; PCR

\section{Introduction}

Toxocara cati (Schrank, 1788) is a common ascarid roundworm of cats and wild felids. In the definitive hosts, the adult forms of T. cati are found in the upper tract of the small intestine and may produce thousands of unembryonated eggs, which pass in faeces, contaminating the environment [1]. Eggs are not immediately infective; embryonation occurs over weeks to months under optimal conditions of temperature and humidity, and embryonated eggs can remain infective in the environment over months to years [2]. The widespread contamination of the environment with Toxocara eggs facilitates infection of both definitive and paratenic hosts, including humans.

Embryonated eggs represent the infective form for the definitive host and for a wide range of paratenic hosts, such as rodents, lagomorphs, ruminants, pigs, and birds. After ingestion by paratenic hosts, larvae penetrate the intestinal wall and migrate via blood system to several organs, including liver, lungs, muscles, and the Central Nervous System (CNS) [3-6].

Human toxocariasis is a parasitic zoonosis, mainly caused by T. canis and T. cati [5].

People can be infected by $T$. canis and T. cati through accidental ingestion of embryonated eggs via contaminated soil, food, or water, or by eating raw or undercooked meat containing Toxocara larvae [7].

Although the larval stages are unable to develop to adult worms in humans, infective Toxocara larvae may migrate to a range of tissues, causing damage to whatever tissue they happen to enter, resulting in a number of clinical manifestations such as visceral larva migrans (VLMs), ocular larva migrans (OLMs), covert or common toxocariasis (CT), and neurotoxocariasis (NT) [8-13]. With any migration paths taken by Toxocara larvae, however, a majority of clinical manifestations caused by Toxocara infection is asymptomatic or non-specific; therefore, its impact on public health could be underestimated $[9,14]$. 
However, the importance of this parasitic zoonosis is increasing in the last few years, and the Centers for Disease Control and Prevention (CDC) listed human toxocariasis among the five most neglected parasitic diseases worldwide [14-16].

Toxocara larvae can be occasionally detected in non-definitive hosts by enzymatic digestion of muscle, collected during routine meat inspection at the slaughterhouse and sent to the laboratory for official controls for Trichinella [17]. Indeed, according to the European legislation "carcasses of horses, wild boar and other farmed and wild animal species susceptible to Trichinella infestation shall be systematically sampled in slaughterhouses or game-handling establishments as part of the post-mortem examination" (EU Regulation 1375/2015) [18].

In Italy, due to increasing popularity of "meat carpaccio", (consisting of thinly sliced raw meat) the presence of Toxocara larvae might represent a source of infection for humans. In this study, we report the detection and molecular identification of T. cati larvae in meat samples of ostrich and wild boars, which were inspected by enzymatic digestion, for trichinellosis control.

\section{Results}

Trichinella larvae were not detected in ostriches or wild boar meat. However, nematode larvae $(\mathrm{n}=8)$, belonging to genus other than Trichinella, were detected in meat samples of two ostriches in September 2019 and in one ostrich in December 2020. All ostriches had been reared in the same farm, sited in the province of Venice (northeastern Italy).

Nematode larvae $(n=4)$ were also found in meat samples of wild boars in December 2020. All larvae were alive and motile when observed under the stereomicroscope. Larvae measured $400-450 \mu \mathrm{m}$ in length and $15 \mu \mathrm{m}$ in width. The anterior part of the body ended in a sub-terminal mouth, while the posterior one tapered to a slender tail. The esophageal region, occupying one-third of the total length, and the more opaque intestinal region were clearly distinguishable. Based on the morphological characters, all larvae were classified as other than Trichinella, which have a greater length $(800-900 \mu \mathrm{m})$ and a different anatomic structure [19].

Molecular identification confirmed the species as Toxocara cati (Figure 1). Phylogenetically, sequences of the Internal Transcribed Spacer 1 (ITS1) region were invariably identical among ostrich and wild boar, with a single sequence type (ST) observed. In a tree (Figure 2), sequences of Toxocara cati clustered into highly supported (bootstrap value $=100 \%$ ) clades, clearly separated from other Toxocara species.

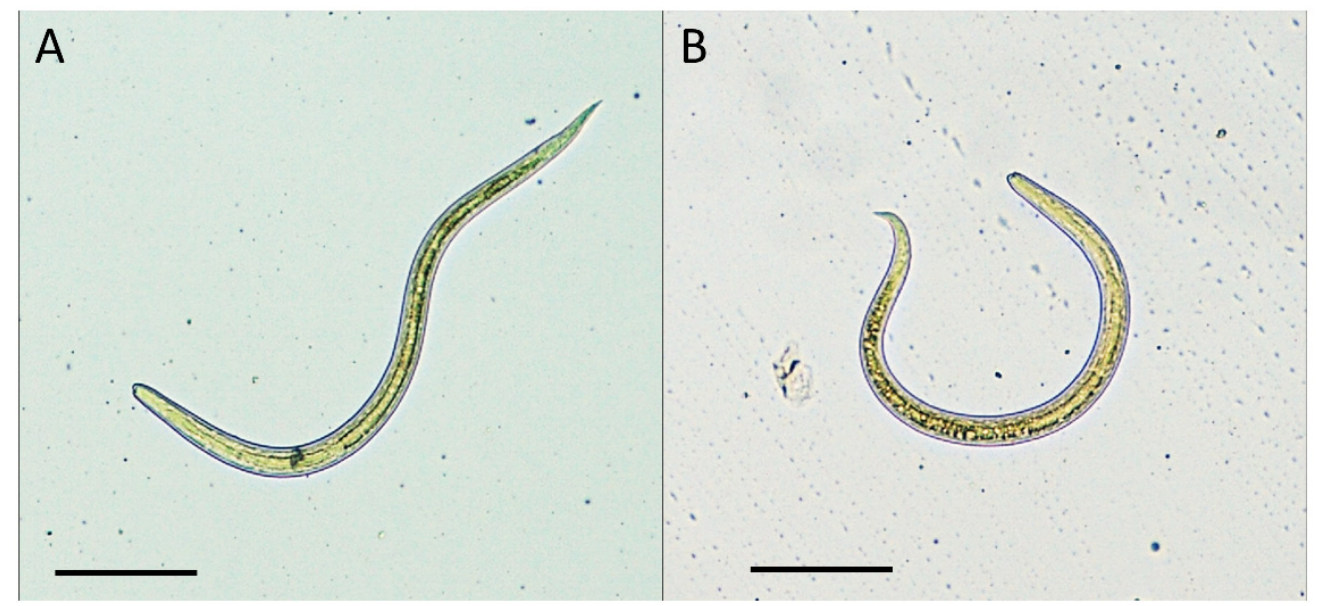

Figure 1. Toxocara cati larvae detected in muscle samples of ostriches (A) and wild boars (B) by artificial enzymatic digestion. Scale bars $100 \mu \mathrm{m}$. 


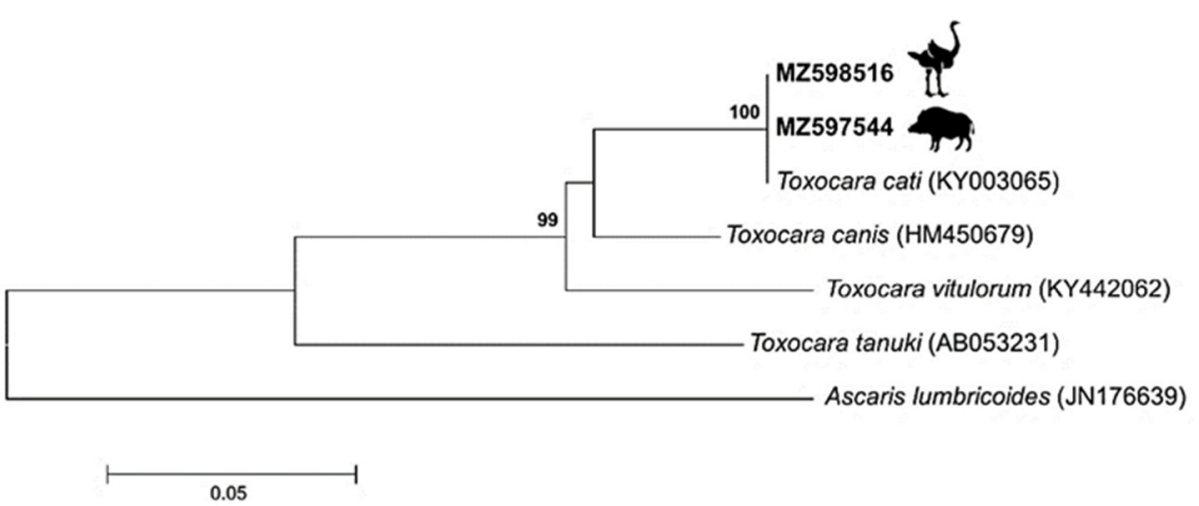

Figure 2. Phylogenetic tree based on Internal Transcribed Spacer 1 (ITS1) sequences of Toxocara species. The tree was constructed using the Neighbor joining method (Jukes Cantor model). Bootstrap values above $90 \%$, indicated at the main nodes, represent the probabilities based on 1000 replicates. The sequences obtained from our study are shown with accession number in bold. Ascaris lumbricoides sequence was used as an outgroup.

\section{Discussion}

In this study, we report the detection of T. cati larvae in ostrich and wild boar muscles. Although T. cati larvae have been already detected in birds and domestic pigs, including chickens and wild avian species of the genera Corvus, Falco, Circus, and Buteo [6,17], the detection of $T$. cati larvae in ostrich and wild boar muscle poses a higher risk of infection for humans, as this meat can be consumed "raw".

Several cases of human toxocariasis occurred after the consumption of raw meat and organs of paratenic hosts, especially raw liver of different animals, including lamb [20] and ostrich [21]. In particular, the consumption of raw ostrich liver caused NT in a young boy, who showed symptoms of eosinophilic meningitis and lungs and liver involvement [21].

In all these cases, the diagnosis of human toxocariasis was based on clinical and serological findings, concluding T. canis was the etiological agent. However, immunological tests show cross reactivity between $T$. canis and T. cati, probably resulting in an overdiagnosis of T. canis-associated infection [2]. This hypothesis might also be supported by results of this study in which all Toxocara larvae belonged to $T$. cati species and not to T. canis.

Animals included in our study were raised at an extensive farm. These animals might have become infected by ingesting embryonated eggs that contaminated in the pasture, or by ingesting other paratenic hosts, such as invertebrates and small rodents.

Toxocara larvae were detected in ostrich meat samples in September 2019 and September 2020. Ostriches were still positive for the presence of $T$. cati larvae in muscle, one year after the first detection. This could be due to the contamination of the pasture with $T$. cat $i$ eggs, which may remain infective in the environment for years [2], or to a recontamination of the pasture with feces from stray cats.

The growing habit of eating raw or undercooked meat, typical of many cultures [21,22], significantly increases consumer exposure to zoonotic parasites which can cause severe disease [23]. Our findings emphasize that the consumption of raw meat increases the risk of Toxocara spp. infection. For this purpose, it is recommended to store the meat at $-20{ }^{\circ} \mathrm{C}$ for at least $48 \mathrm{~h}$, considering that this treatment proved to be effective for inactivating $T$. cati larvae from chicken meat [24]. A similar preventive measure is used for fish species at risk of infection by nematodes larvae of the family Anisakidae, according to the European regulation (CE Regulation 853/2004) [25].

\section{Materials and Methods}

\subsection{Enzymatic Digestion}

From September 2019 to December 2020, 24,098 muscle samples were controlled for Trichinella at the laboratory of Parasitology, Mycology, and Medical Entomology (IZSVe- 
Legnaro, Italy). These samples included 15,804 pigs, 8291 horses and wild boars, and 3 ostriches, and were all collected by the veterinary authority at slaughterhouse as part of the post-mortem examination according to the European Regulation [18].

The analysis consisted of different steps: (i) enzymatic digestion of pooled meat samples (100 g for pool), followed by (ii) filtration, and (iii) sedimentation and observation of the digested material under the stereomicroscope for the detection of nematode larvae according to the EC Regulation 1375/2015 [18] and ISO 18743:2015 [26].

Nematode larvae were individually transferred in $2 \mathrm{~mL}$ tube (one larva per tube) using a pipette with a $100 \mu \mathrm{L}$ tip and stored at minus $20^{\circ} \mathrm{C}$ until molecular analysis was performed.

\subsection{Molecular Tools}

DNA was extracted from a single larva using a commercial kit (DNeasy Blood \& Tissue Kit; Qiagen, Hilden, Germany), following the manufacturer's recommendations. A negative control, consisting of PBS (phosphate buffer solution), was included systematically in each series of DNA extractions. DNA was amplified by PCR, targeting a portion of the Internal Transcribed Spacer 1 region (ITS1) gene.

The following ITS1 primers were used: 18s-ITS1-5.8S for (5'-TAACAAGGTTTCCGTAGGTG -3')-18S-ITS1-5.8S rev (5'-AGCTRGCTGCGTTCTTCATCGA-3') amplifying 650-750 bp [27].

Reactions were performed in $50 \mu \mathrm{L}$ of mix containing AmpliTaq Gold ${ }^{\mathrm{TM}}$ DNA Polymerase with Buffer II and $\mathrm{MgCl}_{2}, 0.5 \mu \mathrm{M}$ of primers, $0.2 \mu \mathrm{M}$ of dNTP (Thermo Scientific), and $5 \mu \mathrm{L}$ of extracted DNA. The PCR cycle is as follows: an initial denaturation step at $95^{\circ} \mathrm{C}$ for $10 \mathrm{~min}$, then 35 amplification cycles (denaturation at $94^{\circ} \mathrm{C}$ for $30 \mathrm{~s}$, annealing at $55^{\circ}$ for $30 \mathrm{~s}$, extension at $72{ }^{\circ} \mathrm{C}$ for $30 \mathrm{~s}$ ) and a final elongation step at $72{ }^{\circ} \mathrm{C}$ for $10 \mathrm{~min}$.

All positive amplicons were sequenced, as described previously [28], for taxonomic confirmation. Molecular phylogeny was performed using Neighbor joining method (Jukes Cantor model) on the ITS1 (MZ598516 - MZ597544) sequence data sets MEGA v.6.0. Bootstrap values shown at the main nodes represent the probabilities based on 1000 replicates. We added sequences of Toxocara cati, T. canis, T. vitulorum, and T. tanuki available from GenBank (https: / /www.ncbi.nlm.nih.gov/nucleotide, accessed on 4 August 2021), using Ascaris lumbricoides as an outgroup.

Author Contributions: Conceptualization, P.D.; formal analysis, V.C., A.Z., S.S. and C.F.; writingoriginal draft preparation, A.M.; and review and editing, P.D. All authors have read and agreed to the published version of the manuscript.

Funding: This research did not receive external funding.

Institutional Review Board Statement: Not applicable.

Informed Consent Statement: Not applicable.

Data Availability Statement: Not applicable.

Acknowledgments: We thank Franco Mutinelli for revisions and suggestions. We thank Susanna Pasqualotto, Elena Porcellato, and all colleagues who supported the laboratory activities during the manuscript realization.

Conflicts of Interest: The authors declare no conflict of interest.

\section{References}

1. Parsons, J.C. Ascarid infections of cats and dogs. Vet. Clin. N. Am. Small Anim. Pract. 1987, 17, 1307-1339. [CrossRef]

2. Fisher, M. Toxocara cati: An underestimated zoonotic agent. Trends Parasitol. 2003, 19, 167-170. [CrossRef]

3. Glickman, L.T.; Schantz, P.M. Epidemiology and pathogenesis of zoonotic toxocariasis. Epidemiol. Rev. 1981, 3, 230-250. [CrossRef] [PubMed]

4. Strube, C.; Heuer, L.; Janecek, E. Toxocara spp. infections in paratenic hosts. Vet Parasitol. 2013, 193, 375-389. [CrossRef] [PubMed]

5. Bowman, D.D. The anatomy of the third-stage larva of Toxocara canis and Toxocara cati. 1st ed. Adv. Parasitol. 2020, $109,39-61$.

6. Wu, T.; Bowman, D.D. Visceral larval migrans of Toxocara canis and Toxocara cati in non-canid and non-felid hosts. Adv. Parasitol. 2020, 109, 63-88. 
7. Sterling, C.R. Food-Borne Nematode Infections. In Foodborne Parasites. Food Microbiology and Food Safety Series, 1st ed.; Ortega, Y.R., Ed.; Springer: Boston, MA, USA, 2006; pp. 135-160.

8. Magnaval, J.F.; Glickman, L.T.; Dorchies, P.; Morassin, B. Highlights of human toxocariasis. Korean J. Parasitol. $2001,39,1-11$. [CrossRef]

9. Rubinsky-Elefant, G.; Hirata, C.E.; Yamamoto, J.H.; Ferreira, M.U. Human toxocariasis: Diagnosis, worldwide seroprevalences and clinical expression of the systemic and ocular forms. Ann. Trop. Med. Parasitol. 2010, 104, 3-23. [CrossRef] [PubMed]

10. Finsterer, J.; Auer, H. Parasitoses of the human central nervous system. J. Helminthol. 2013, 87, 257-270. [CrossRef]

11. Nicoletti, A. Toxocariasis. Handb. Clin. Neurol. 2013, 114, 217-228.

12. Ma, G.; Holland, C.V.; Wang, T.; Hofmann, A.; Fan, C.K.; Maizels, R.M.; Hotez, P.J.; Gasser, R.B. Human toxocariasis. Lancet Infect. Dis. 2018, 18, 14-24. [CrossRef]

13. Auer, H.; Walochnik, J. Toxocariasis and the clinical spectrum. Adv. Parasitol. 2020, 109, 111-130.

14. Chen, J.; Liu, Q.; Liu, G.H.; Zheng, W.B.; Hong, S.J.; Sugiyama, H.; Zhu, X.Q.; Elsheikha, H.M. Toxocariasis: A silent threat with a progressive public health impact. Infect. Dis. Poverty 2018, 7, 59. [CrossRef]

15. Macpherson, C.N. The epidemiology and public health importance of toxocariasis: A zoonosis of global importance. Int. J. Parasitol. 2013, 43, 999-1008. [CrossRef] [PubMed]

16. Centre for Disease Control and Prevention. Available online: https://www.cdc.gov/parasites/npi/ (accessed on 24 August 2021).

17. Marucci, G.; Interisano, M.; La Rosa, G.; Pozio, E. Molecular identification of nematode larvae different from those of the Trichinella genus detected by muscle digestion. Vet Parasitol. 2013, 194, 117-120. [CrossRef] [PubMed]

18. European Commission. Commission Implementing Regulation (EU) 2015/1375 of 10 August 2015 laying down specific rules on official controls for Trichinella in meat. Off. J. Eur. Union 2015, 58, 7-34.

19. Euzéby, J. Recherche des larves de Trichines dans des biopsies de muscles sous-cutanes chez le porc. In Diagnostic Expérimental des Helminthoses Animales; Tome, I., Ed.; Informations Techniques Vétérinaires, Bulletin de l'Académie Vétérinaire de France Année: Paris, France, 1982; pp. 139-140.

20. Salem, G.; Schantz, P. Toxocara visceral larva migrans after ingestion of raw lamb liver. Clin. Infect. Dis. 1992, 15, 743-744. [CrossRef] [PubMed]

21. Noh, Y.; Hong, S.T.; Yun, J.Y.; Park, H.K.; Oh, J.H.; Kim, Y.E.; Jeon, B.S. Meningitis by Toxocara canis after ingestion of raw ostrich liver. J. Korean Med. Sci. 2012, 27, 1105-1108. [CrossRef]

22. Yang, H.K.; Woo, S.J.; Hwang, J.M. Toxocara optic neuropathy after ingestion of raw meat products. Optom. Vis. Sci. 2014, 91, e267-e273. [CrossRef]

23. Macpherson, C.N.L. Human behaviour and the epidemiology of parasitic zoonoses. Int. J. Parasitol. 2005, 35, 1319-1331. [CrossRef]

24. Taira, K.; Saitoh, Y.; Okada, N.; Sugiyama, H.; Kapel, C.M.O. Tolerance to low temperatures of Toxocara cati larvae in chicken muscle tissue. Vet Parasitol. 2012, 189, 383-386. [CrossRef] [PubMed]

25. Regulation (EC) No 853/2004 of the European Parliament and of the Council of 29 April 2004 laying down specific hygiene rules for food of animal origin. Off. J. Eur. Communities 2004, 102-109. Available online: https: / eur-lex.europa.eu/eli/reg/2004/853/oj (accessed on 6 October 2021).

26. UNI EN ISO 18743:2015 Microbiology of the Food Chain. Detection of Trichinella Larvae in Meat by Artificial Digestion Method. Available online: https:/ / www.iso.org/standard/63251.html (accessed on 4 August 2021).

27. Kang, S.; Sultana, T.; Loktev, V.B.; Wongratanacheewin, S.; Sohn, W.M.; Eom, K.S.; Park, J.K. Molecular identification and phylogenetic analysis of nuclear rDNA sequences among three opistorchid liver fluke species (Opistorchidae: Trematoda). Parasitol. Int. 2008, 119, 191-197. [CrossRef] [PubMed]

28. Danesi, P.; Falcaro, C.; Dukik, K.; Jiang, Y.; Rizzoli, A.P.; Allavena, R.; Simpson, V.; Ravagnan, S.; Zanardello, C.; Capelli, G.; et al. Molecular Diagnosis of Emmonsia-Like Fungi Occurring in Wild Animals. Mycopathologia 2019, 185, 51-65. [CrossRef] 